\title{
A Study on the Roentgen Aspect of Tuberculosis of the Joints and its Relation to the Clinical Aspect, especially when under Treatment by Universal Light Baths
}

\author{
by \\ Edvard Collin
}

Works on this subject are only to be found scattered through surgical text-books and review articles. Nowhere have I found any attempt to render a collective description of the course of tuberculosis of the joints, notably not of its roentgenological relationship, and especially not when under treatment by universal light.

In Svenska Läkaresällskapets Handlingar, vol. 42, 1916, and in Archives of Radiology and Electrotherapy vol. 25, 1921, Professor GösTA FORSSELL has published a series of roentgen pictures of jointtuberculosis in order to show the variety of changes which are regarded as typical.

In his book »La cure de soleil» RoLLIER mentions the roentgen aspect of tuberculosis of the bones before and after sunlight treatment, but has not followed the intermediate stages of its development.

JOHS. IPSEN, in his work »Importance of roentgen examination for the diagnosis of tuberculosis of bones and joints», 1916, has carried out an examination of the relationship between the clinical, roentgenological, and operative findings in tuberculosis of the joint. The subject, then, is not identical with mine, but the works touch, and the large material which IPSEN, on the encouragement of Prof. Rovsing, presents (from C. Division of Rigshospitalet) is very instructive when judging the roentgen plates with tuberculosis of the bones. I shall not further enter upon a discussion of IPSEN's work, and would only say that, amongst other things, he fails to give us $\gg$ a collective description of the changes in the roentgen plates peculiar to tuberculosis», just as in his material the initial stages are lacking. The present work may, 
I think, amongst other things, contribute towards the remedy of this deficiency, even if it is far from satisfactory in its present form.

$\mathrm{KISCH}$, in his book, „Diagnostik und Therapie der Knochen und Gelenktuberkulose», 1921, gives a series of views which are to a certain extent to the same effect as the present material, but the therapeutics employed by him are different, namely, Bier's stase treatment with oxygen acetylene source of light, which also seems to give good results.

At the Finsen Institute there is a plentiful opportunity of following these forms of tuberculosis, and during the last few years we have begun systematically to follow the patients roentgenologically, with 3 months' interval so far as possible, as a clinical examination takes place simultaneously with the roentgen examination. In this manner one succeeds in getting a "good aspect of the osteological development and healing of tuberculosis under predominant conservative treatment. At the same time one gets - as planned in this work - an idea of the relation between the clinical and the osteological development.

I regard this work, as, if anything, an experiment. During the 2 years when I have had charge of the roentgen examination of surgical patients, I have noted, amongst other things, the series of examinations which showed typical aspects of tuberculosis, but as the period at my disposal has been only a short one, the material is deficient, especially as regards the affections which require longer treatment (coxitis and spondylitis, for example). On the other hand there is a rich material of hand, foot, and elbow affections, of which I have made a selection which finely demonstrates these localizations. I have chosen series which I consider typical as regards the clinical as well as the roentgenological aspect, and let them run parallel. After each series with its history a summary follows, which is a conclusion of what the history in question shows. The clinical examinations have been carried out by Doctor ERNST who, as the Finsen Institute's surgeon, has conducted the treatment of surgical tuberculosis at the clinic for skin diseases.

On account of the expense of producing the illustrated material and for lack of space I have limited the picture series to comprising the initial stage $1-4$, the intermediate stages, and the final stage. Moreover, I have been obliged to cut out entirely some of the picture series, but have retained the clinical and roentgenological descriptions of the histories, and the conclusions. 


\section{Histories with Concluisons}

No. 1. 1. Patient No. 5426, M. P. Aged 3 years. Boy (Figs. 1-4).

Arthr. tub. genus sin. .

Clinic. $23 / 7$ 19. During the last few days patient complained of pain above left knee. Doubtful swelling on medial side. No impact. Flexion free, extension to $170^{\circ}$. Sensitiveness to palpation. Moderate swelling of capsule.

$29 / 7$. Very weak, cries at least touch of knee. Will not stand on leg. Rp. Plaster of Paris bandage.

Roentgen. ${ }^{29} / 7$ 19. Medial joint-corner of condylus med. femoris destroyed. Indistinctly defined. Also distinct capsular swelling.

Clinic. $9 / 120$. Very considerable swelling of capsule of left knee. Almost no tenderness here. No impact of patella. Motility $90^{\circ}-180^{\circ}$.

Roentgen. ${ }^{10} / 2$ 20. Destruction on epicondylus med. fomoris has propagated considerably, as nearly entire half of epiphysis is destroyed. Joint-fissure not distinctly contracted.

Clinic. $21 / 520$. Some swelling below patella. Infiltration of capsule well diminished. Motility $180^{\circ}-150^{\circ}$. Active. (New plaster of Paris bandage).

Roentgen. $21 / 6$ 20. Distinct healing of process in Condyl. med. with new formation of bone, and distinct definition of focus.

Clinic. 5/4 21. No complaints. Position of knee good. No swelling of capsule. No tenderness. Motility $180^{\circ}-110^{\circ}$.

Roentgen. $5 / 421$. Considerably improved bone structure. New formation of condylus med., contours still somewhat irregular.

Treatment. Universal quicksilver - quartz. light, plaster of Paris bandages.

Conclusion. 1) A tuberculous affection often propagates - especially seen roentgenologically - during the beginning of the light-bath treatment, and latent foci manifest themselves in order to heal after this »period of re-action». 2) The roentgenological improvement reveals itself in a distinctly defined focus, and by new formation of bone in the surroundings.

No. 2. Patient No. 7435, L. H. Aged 1 year, Girl. (Figs. 5 6, 7).

Ostitis tub. ulnae sin.

Clinic. $21 / 10$ 20. During the last few months inspissation of proximal $1 / 3$ of left fore-arm, and tenderness here. Swelling observed localized to ulna and fleshy parts. Circumference $+1.3 \mathrm{~cm}$. Elbow-joint free apart from restricted rotation. Fluctuation below olecranon.

Roentgen. ${ }^{2} \mathrm{i} / 10$ 20. Left elbow, considerable periosteal stratification on ulna. Structure obscure and irregular. Process comprises proximal $1 / 3$ of ulna as far as nucleus of olecranon.

Clinic. ${ }^{4}, 2$ 21. Slight secretion from fistulas (after incision $2 \% / 11$ ). Some increase in thickness round ulna. Free motility.

Roentgen. $9 / 221$. Improved structure, Boundary between original contour of ulna and the periostitis almost gone. Commencing structure formation in the latter.

Clinic. $29 / 6$ 21. Arm reliable. Somewhat restricted rotation. Fistulas firmly closed. No swelling or tenderness. 
Roentgen. ${ }^{21} / ; 21$. Structure completely natural. Only slight indication of periostitis visible on the dorsal side.

Treatment. Universal quicksilver - quartz light. Incision.

Conclusion. A considerable ostitis (ulnæ) can heal without a trace, and with complete restitutio ad integrum (roentgenologically and clinically).

No. 3. Patient 3395. K. S. Aged 2 years. Boy (Figs. 8, 9).

Spina ventosa digiti IV manus d.

Clinic. ${ }^{13} / 5$ 19. Considerable swelling of right hand, corresponding to metacarpus II. Unquestionable spina ventosa of base of $4^{\text {th }}$ finger. Doubtful spina ventosa of base of $2^{\text {nd }}$ and $3^{\text {rd }}$ fingers, and also of metacarp. IV.

Roentgen. ${ }^{13} / 5$ 19. Right hand. Metacarp. II and IV, and phalanx I of $4^{\text {th }}$ finger seen to be seat of typical spina ventosa in 3 different stages (central destruction, periosteal stratification, and obliteration of structure, and immense thickening of the bone). Incipient ostitis in Metacarp. $\mathrm{V}$ is also seen, but no osseous changes at base of $2^{\text {nd }}$ and $3^{\text {rd }}$ fingers.

Clinic. $24 / 4$ 20. Nothing to remark in right hand.

Roentgen. $21 / 420$. Nothing abnormal whatever is seen in right hand, especially not in previously affected bones, the structure of which is now completely normal.

Treatment. Universal quicksilver - quartz light.

Conclusion. 1) On the same hand there may be found all stages of spina ventosa, from commencing obliteration of structure through great destruction and periostitis to complete healing. 2) Spina ventosa at times shows itself earlier roentgenologically than clinically. 3) Spina ventosa with excessive destruction can heal up without a trace.

No. 4. Patient 3732. T. E. Aged 10 years. Boy (No Fig.)

Spina ventosa metacarp. III, IV, $V$, manus d. fist.

Clinic. $1 / 5$ 18. During 8 years boils» on right hand. Treated operatively, constant relapse. Considerable swelling of back of hand with 2 loose ulcerations about the size of a 3-penny piece witl thickening of metacarp. IV and $\mathrm{V}$ is seen.

Roentgen. $6 / 5$ 18. Right hand. Considerable and irregular forcing up of metacarp. III, IV, V, central destruction. Irregular bone formation. Mixture of old and new tuberculous processes.

Clinic. $18 / 8$ 20. Hand has been completely healed for 8 months. Strength good, and full function.

Roentgen. $13 / 8$ 20. Fine healing up of the processes with newly-formed strong and normal structure, and smoothing-down of contours.

Treatment. Carbon arc-light.

Conclusion. 1) Tuberculous ostitis can heal spontaneously, but cosmetically and osteologically the result is far nicer after light treatment, being also considerably expedited. 2) Extensive spina ventosa which has been operatively treated during 8 years, with constant relapse, heals nicely with 6 months' treatment by light. 
No. 5. Patient 4332 . K. J. 20 years. Woman (Figs. 10, 11).

Ostitis ulnae d. c. abscessu. Arthr. carpi.

Clinic. $22 / 10$ 18. During about 8 months pains, swelling, and tenderness of distal III of ulna side of left fore-arm. Treated with fomentation. There is now considerable swelling and $»$ soreness from boils». Motility of wrist restricted to half. Rotation completely ceased.

Roentgen. $23 / 10$ 19. Right wrist region. In extrem. inf. ulnæ is an illumination the size of a nut merging into proc. styl. and occupying part of the articular surface. There are also considerable periosteal coverings on the inner side of ulna, a little higher up, also small illuminations in the bone here.

Clinic. $23 / 420$. Can use hand for light work. No swelling, fistula, or atrophy. Supination a little restricted. Other movements free.

Roentgen. $29 / 4$ 20. Process completely healed up. Structure and contour of ulna seen to be normal.

Treatment. Carbon arc-light. - Puncture.

Conclusion. A large ostitis extrem. inf. ulnæ with affection of the joint can heal without a trace clinically as well as roentgenologically in adults.

No. 6. Patient 6417. G. J. Aged 12 years. Girl (Figs. 12, 13, 14, 15, 16). Spina ventosa metacarpi $I V$ d.

Clinic. 18/2 20. During 3 months swelling and pains in back of right hand. There is now moderate swelling over caput of metacarp. IV. Considerable tenderness, atrophy, and muscular relaxation. Also slightly restricted motility of $4^{\text {th }}$ finger.

Roentgen. 2\% 20. Right hand. Typical very pronounced spina ventosa of metacarp. IV, with heavy periosteal covering on distal half of diaphysis and considerable central destruction here.

Clinic. $21 / 620$. Constant visible swelling of metacarp. IV, where solid, osseous thickening can be felt. Finger movements free. $4^{\text {th }}$ finger shortened about $1 \frac{1}{2} \mathrm{~cm}$.

Roentgen. 14/5 20. Settling of diaphysis of Metacarp. IV, which is greatly deformed, but with commencing structure formation in the part destroyed.

Clinic. $3 / 920$. No complaints. Still slight osseous swelling though less than before.

Roentgen, $1 \% / 20$. Increasing structure formation. Caput metacarpi has settled into the diaphysis, and here is almost hidden by the periostitis.

Clinic. $8 / 1220$. No pains. Hand unchanged.

Roentgen. $9 / 12$ 20. Increasing structure, and distinct tapering of Metacarp. IV.

Clinic. $13 / 421$. Right hand completely natural apart from insignificant swelling of metacarp. IV.

Roentgen. 21/6 21. Nice, almost completely natural and strong structure, with smoothing-down of the contour. Metacarpus has resumed its natural form, but is shortened about $1 \mathrm{~cm}$.

Treatment. Carbon arc-light.

Conclusion. Clinical and roentgen examinations show a typical development and healing of a severe ostitis metacarpi (spina ventosa).

The tuberculous ostitis can be indicated in 3 stages. 1) Obliteration of structure. 2) Periosteal re-action, and visible central destruction with forcing-up of the bone. 3) Smoothing-down of the periostitis with new formation of the natural shape and structure of the bone. 
No. 7 A. Patient 6074. V. L. Aged 5 years. Boy (Figs. 17, 18, 19, 20).

Arthr. tub. pedis sin. (Arthr. tub. manus dext.) (Epididymitis tub. sin. (Otitis med. supp.).

Clinic. $27 / 11$ 19. For about 6 months general relaxation and swelling of left anklejoint (of left scrotal half and right carpus). There is now diffuse swelling rouud both malleoli $(+1 \mathrm{~cm}$.$) . Motility completely free. No pains. No tenderness.$

Roentgen. $8 / 12$ 19. Left ankle-joint. Nothing abnormal apart from slight atrophy of the bone.

Clinic. $8 / 720$. Considerable fluctuating swelling behind left mall. int. No tenderness. Motility $110^{\circ}-130^{\circ}$. Side movements free.

Roentgen. $1 / 7$ 20. Left ankle.joint, considerable destruction of articular surfaces on tibia and talus. $(19 / 320$, the articular surface of tibia found somewhat uneven).

Clinic. $11 / 3$ 21. Left foot stands in somewhat tapering position. Only doubtful thickening round the ankle-joint itself, but more thickening round mall. int. No pains. Side movements free.

Roentgen. $3 / 3$ 21. Left ankle-joint. In all essentials conditions as on $27 / 1120$, though, if, anything, with increase of destruction. But at the same time with improved structure in the adjoining bone. $\left({ }^{26 / 11}\right.$ complete obliteration of joint-fissure, and considerable atrophy of the bone).

Clinic. $5 / 721$. Left foot forms an angle of about $120^{\circ}$, with very slight flexion motility of crus. Side movements good. Distinct infiltration behind both malleoli. No tenderness or pains.

Roentgen. ${ }^{20} / 6$ 21. Left ankle joint. The process does not seem to be propagated. Structure better. The contours of the articular surfaces of talus and tibia can be seen, and a joint-fissure seems to be re-forming.

Treatment. Quicksilver - quartz light. Confinement to bed. Plaster of Paris bandage. Also treatment of patient's other affections (hand, epididymis, ear). $N . B$. Patient still under treatment.

Conclusion. 1) Tuberculous arhroitis most often reveals itself first clinically and later roentgenologically. 2) Even if propagation of arthroitis is found roentgenologically, there may quite well be an improvement clinically, and certainly the latter best expresses the condition.

No. 7 B. Patient 6074 . V. L. Aged 5 years. Boy (Figs. 21, 22, 23, 24).

Arthr. tub. manus dext.

Clinic. $27 / 11$ 19. Diffuse swelling over entire back of right hand, concerning both bones and capsule. Great tenderness. Movement of wrist very restricted.

Roentgen. 8/12 19. Right hand. Nothing abnormal apart from some bone atrophy.

Clinic. ${ }^{11}-26 \% 320$. Considerable swelling of right hand, especially over the radiocarpal joint, extending to centre of middle of hand. Dorsalflex. $0^{\circ}$, volarflex. $70^{\circ}$, radialflex. $0^{\circ}$, tunarflex. $20^{\circ}$, pro- and supination free. Great tenderness.

Roentgen. ${ }^{27 / 3}$ 20. Right wrist. Unquestionable destruction of all carpal bones, espcially of os capitatum and os hamatum, also base of metacarp. III and especially metacarp II, with indistinct outline of the defects, and considerable diffuse bone atrophy.

Clinic. $23 / 11$ 20. General condition good. Some diffuse swelling of hand, no tenderness. Motility almost as on $11 / 320$.

Roentgen. ${ }^{26} / 1120$. Destruction of carpal bones essentially increased, especially the entire proximal half of os capitatum has settled and the remaining part forms 
an inseparable conglomeration with all neighbouring bones. Only os multangulum minus seems to have escaped. In spite of this increased destruction there is however, improved structure in what remains.

Clinic. $19 / 5-5 / 721$. General condition good. Now only slight swelling of right wrist. Only slight infiltration can be felt. Dorsal flex. $0^{\circ}$, volar flex. $60^{\circ}$, ab-and adduct. good. Pro- and supination free. Handshake vigorous.

Roentgen. $27 / 621$. Structure of all bones now almost natural. The contours sharply portraying considerable defects, but with commencing new formation of the joint-fissures.

Treatment. Quicksilver - Quartz light - Splint bandage.

Conclusion. 1) In the initial stage of tuberculous arthroitis considerable clinical changes may be found, without one being able to prove anything abnormal roentgenologically; one may do so several months later. 2) Together with clinical improvement there may be seen considerable roentgenologic deterioration, but improved structure in the surroundings (or bone remains) is seen as a sign of the limit of the process.

No. 8. Patient 5255. E. R. Aged 2 years. Girl. (Figs. 25, 26, 27, 28).

Arthr. tub. cubiti sin. c. abscessu. Ostit. tub. multilocularis.

Clinic. $12 / 519$. Two months ago trauma of left elbow, after which swelling and restricted motility. Now there is diffuse swelling of the bones and fleshy parts ( $+1.5 \mathrm{~cm}$.) Motility $60^{\circ}-140^{\circ}$. Pro- and supination free. No tenderness or pains. Skin on the back thin and cyanotic.

Roentgen. $16 / 5$ 19. Left elbow. Considerable destruction of extrem. sup. ulna including the articular surface; also considerable periosteal coverings. Humerus and radius free.

Clinic. $3 / 9$ 19. Swelling somewhat decreased. Movements a little freer.

Roentgen. ${ }^{24} / 8$ 1919. Destruction unmasked, occupies part size of large walnut. Is sharply defined against the adjoining sound parts of the bone (dorso-distally), where denser bone tissue is seen (re-action). Periostitis well diminished and of almost same density and structure as the bone.

Clinic. 15/5 20. No complaining. Uses his arm. No apparent swelling of elbow. No tenderness. Motility $50^{\circ}-135^{\circ}$. Pronat. free. Supinat. minus $15^{\circ}$. No atrophy.

Roentgen. $15 / 520$. Considerable and nice healing-up of the process with new formation of destructed portion and of articular surface. Periostitis completely disappeared, contour smooth, structure still somewhat irregular, but dense.

Clinic. $1 / 621$. Arm completely in order. Nothing to remark about it. Motility free.

Roentgen. $6 / 721$. Ulna now seen natural. Structure and contours regular and nice.

Treatment. Quick silver. Quartz light.

Conclusion. A considerable destruction in extrem. sup. ulnæ with affection of the joint can heal without a trace and with complete restitutio ad integrum.

No. 9. Patients 3889. J. J. Aged 28 years. Woman. (Figs: 29, 30).

Arthr. manus tub. dext. c. abscess. (Tub. pulm. adenit. colli).

Clinic. $4 / 4$ 18. During about 3 months a slowly growing tender swelling on radial side of left wrist. Has not been able to attend to her occupation (piano). 
Now the left wrist is seen placed fully extended, pronated, about $20^{\circ}$ radial inflected, firmly fixed. Dorsal flex. $0^{\circ}$, volar flex. $40^{\circ}$, side movements 0 . Considerable swelling of entire joint, especially round the radial side, where there is an abscess hardly the size of a hen's egg. Severe atrophy. Weak handshake.

Roentgen. $3 / \%$. Left wrist. Uneven periosteal covering on the outer side of extrem. inf. radii. No distinct bone focus. Patchy and extensive bone atrophy in all wrist bones. Joint-fissures all seem well preserved.

Clinic. $2 / 1$ 1920. An ulceration on hand has been healed for about 9 months. She has used her hand for light work and piano for about 6 months. No pains. Position of hand natural. Dorsal flex. $80^{\circ}$, volar flex. $80^{\circ}$, ulnar flex. $0^{\circ}$, radial flex. natural $\left(30^{\circ}\right)$ Pro- and supination free. No swelling. Some atrophy. Handshake a little weaker than on left side.

Roentgen. $\% / 120$. Left wrist. The periostitis on radius completely disappeared. In its place is seen a somewhat irregular flat defect sharply defined, the result no doubt of a now firmly healed process here. Structure in all bones now seen completely natural.

Treatment. Universal carbon arc-light, and local light treatment. $\left({ }^{25} / 8,20\right)$. Hand now completely natural without a trace of swelling or restriction of movement. Plays much as music-teacher. Roentgen picture now shows completely natural conditions.

Conclusion. An extensive tuberculosis of the wrist (in adults) with affection of capsule and bones can heal completely with restoration of normal appearance, free motility, and full strength.

No. 10. Patient 6625. A. P. Aged 20 years. Woman (No Figure).

Arthr. tub. cubiti sin.

Clinic. $9 / 420$. About 3 years ago weakness and restricted movement began in left elbow. Later pain with movement and swelling of joint. The condition deteriorated under treatment with quartz light (infirmary), and improved under treatment with sun-baths. Left elbow is now seen inflected to $135^{\circ}$, and from here about $15^{\circ}$ active and passive movement. Tenderness on epicond. lat. and pains with movement. Atrophy of upper arm and fore-arm. Considerable diffuse swelling with obliteration of the contours.

Roentgen. $9 / 420$. Left elbow. Considerable destruction of extrem. sup. ulnæ, with entire facies articularis; neither this nor trochlea is seen, and the whole of this area forms a structureless whole only sharply defined from the adjacent part of the bone. On the outside of extrem. inf. humeri some periosteal covering is seen. No doubt it is a question of an old propagating tub. arthr.

Clinic. $17 / 2$ 21. No complaints. Uses the arm a little every day. Thinks there is good progress. Very slight diffuse swelling of left eloow is now seen. Motility $100^{\circ}-130^{\circ}$ (active). No pains. Supination to edgewise position. Pronation free.

Roentgen. 21/1 21. Left elbow. One now sees a distinct joint-fissure of about normal width, but somewhat irregular and indistinct. New bone tissue has formed both in ulna and humerus, though in both still a defect corresponding with the articular surfaces. Destruction of capitulum radii also seems to have taken place, but the structure here as in the other bones is now quite good though still somewhat halisteretic.

Treatment. Carbon arc-light. Mitella.

Conclusion. Considerable tuberculous arthroitis in the elbow-joint (in adults) can heal with new formation of articular cartilage and good function. 
No: 11. Patient 4096. L. J. Aged 29 years. Woman (Figs. 31, 32, 33).

Arthr. tub. humeri sin. (Tub. pulm).

Clinic. $20 / 7$ 18. About 18 months ago pains began in left shoulder, treated with massage. A little later treated at sanatorium for tub. hæmoptysis). A month ago sudden severe pains in left shoulder, which went away with rest. Can now use the arm again (Roent. picture on $22 / 418$ showed nothing abnormala part from slight atrophy - Panner). Slight atrophy of $\mathrm{m}$. deltoideus is now seen. No tenderness. Abduction slightly restricted, also circumduction, which causes a good deal of pain. No grinding.

Roentgen. $1 / 11$ 18. Left shoulder. Nothing abnormal apart from slight atrophy. of the bone.

Clinic ${ }^{4} / 1020$. A good deal of unrest in left shoulder, but no real pains. Works in a factory; can't bear to lift her arm. Insignificant atrophy of deitoideus. Motility completely free.

Roentgen. $23 / 10$ 20. Left shoulder. There is now seen a falcate, nail-sized defect ca. $1 \mathrm{~cm}$. deep on upper part of caput humeri, continuing as an indistinctly defined illumination into the bone, no doubt as a sign of a tuberculous focus which had not manifested itself at roentgen exam. ${ }^{11 / 1} 18$.

Clinic. $22 / 621$. On and off pain in left shoulder. Nothing new at examination. Motility quite free.

Roentgen. $23 / 4$. Left shoulder. The defect mentioned seen a little larger than on $23 / 1020$, but sharply defined, and with strong bone structure in the surroundings. The process thus seems to have quieted down.

Treatment. Carbon arc-light (with long interruptions of intercurrent illnesses and stays in sanatorium).

Conclusion. 1) Tuberculosis of the shoulder-joint (in adults) may limit itself and finally result in a joint completely capable of function. 2) A clinically suspected affection of caput humeri may present a normal roentgen aspect. The area around tuberculum maj. is particularly difficult to judge, and the tuberculosis is often found just at this place answering to the capsular attachments.

No. 12. Patient 4576. K. T. Aged 9 years. Girl (Figs. 34, 35, 36).

Arthr. cubiti sin. Ostitis p. mag. ulnae. c. abscessu.

Clinic. $\% 1 \%$ 18. About 9 months ago pains, tenderness, and some swelling of upper third of left fore-arm. Condition rather stationary. No treatment. Is now found distally from left olecranon an abscess the size of a hen's egg ( $7 / 1218$ punctured, after which injection of indoform glyc.) The capsule of the elbow-joint somewhat distended. Skin natural. Motility $160^{\circ}-60^{\circ}$.

Roentgen. 11/1: 18. Left elbow. Extrem. sup. ulnæ seat of enormous forcing-up, especially in front and medially. Also 3 large illuminations up to the size of a pigeon's egg are seen in the bone, rather sharply defined. The contours of ulna also rather sharp, and without distinct periosteal covering. One cannot decide how far the articular surface is affected. The process resembles a severe tuberculous ostitis, with tendency to heal. Dorsally of ulna is seen the injected iodoform.

Clinic. $24 / 9$ 19. Has been to country for 4 months. Had light baths during 5 months. After these $(2 / 5,19)$ no pains. Motility $50^{\circ}-175^{\circ}$. Supination slightly restricted. Slight swelling round ulna. Appearance now all right. Slight thickening of ulna. Motility quite free. No abscess. 
Roentgen. $29 / 9$ 19. Left elbow-joint. Swelling of ulna considerably diminished. Illuminations fewer and smaller, and all contours show up sharply. Structure good. Iodoform resorbed.

Clinic. $2: 3 / 6$ 21. Left elbow-joint. During last 6 months $(9 / 120)$ has been completely normal in appearance and motility. Nothing abnormal now.

Roentgen. $23 / 621$. Left elbow. In the centre of extrem. sup. ulnæ a cavity the size of good-sized nut, sharply defined from completely natural bone tissue. For the rest, the bone further reduced and seen to be of normal width in dorsivolar projection.

Treatment. Quartz light, carbon arc-light, quartz light (N. B. Patient has had no erythema, and hardly any pigmentation.)

Conclusion. 1) Tuberculous ostitis showing tendency to heal and left to itself displays a very irregular method of healing (osteologically), but under light treatment more approaches natural conditions. 2) No inconsiderable deformity of extrem. sup. ulnæ with central defect can exist simultaneously with a good function of the joint.

The extracts of histories and roentgen examinations with conclusions here reported are, as mentioned above, extracts from a larger material showing the conditions which, by the examples given, I think I can establish as of universal validity and not exceptional. If the principles here given for roentgen examination are followed for a few years one will through this no doubt obtain a very fine material for judging the osteological conditions of tuberculosis of the bones with conservative treatment, and hereby arrive at a more pregnant conception of the im. portance of light treatment.

My preliminary material shows, I think, various interesting conditions of surgical tuberculosis, as proved by the conclusions. Now I shall only emphasize a few of them as a summary.

\section{Summary}

1) Even if the roentgen aspect reveals no sign of tuberculous changes, it doesn't exclude the possibility of the affection being tuberculous (History No. 7 B and No. 11).

2) Sometimes the roentgenological changes only come at a moment when the clinical symptoms have considerably improved, (History No. $7 \mathrm{~A}$ and 7 B) as first emphasized, I think, by ERNsT.

3) The light treatment of surgical tuberculosis can yield extremely fine results, even where serious roentgenological changes are found, for which reason one cannot, on the basis of these alone, give a bad prog- 


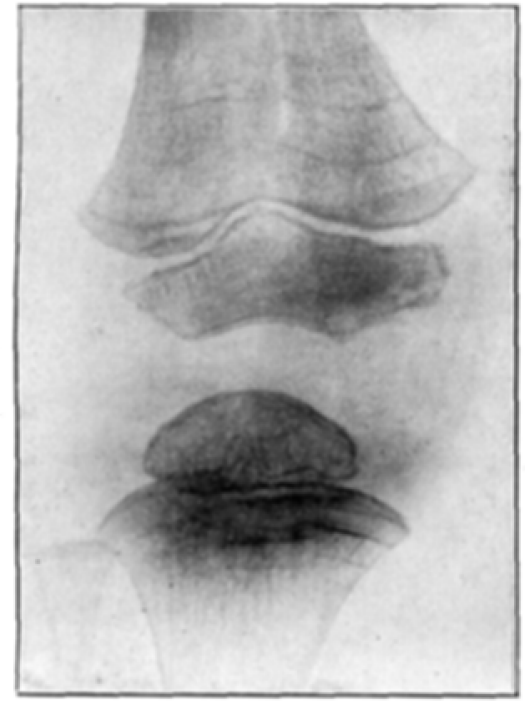

Fig. 1

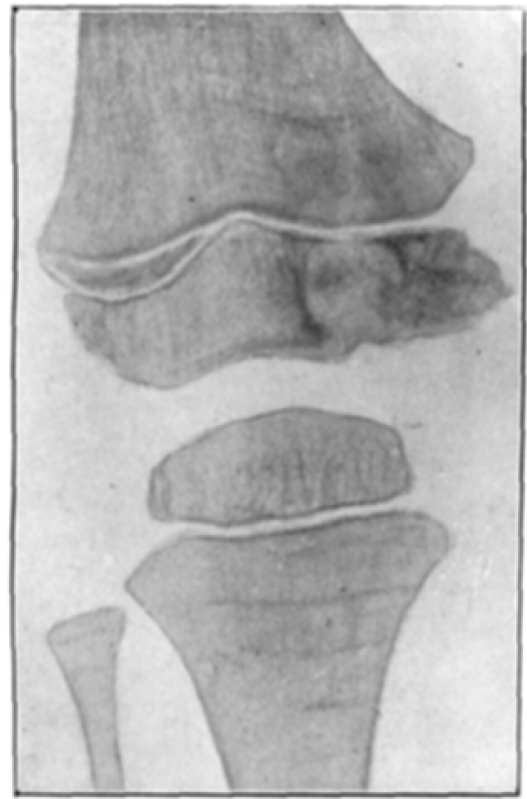

Fig. 3

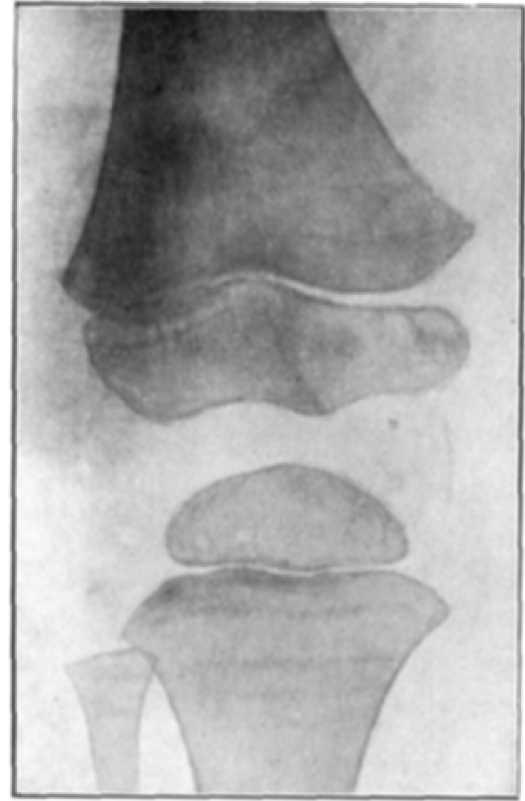

Fig. 2

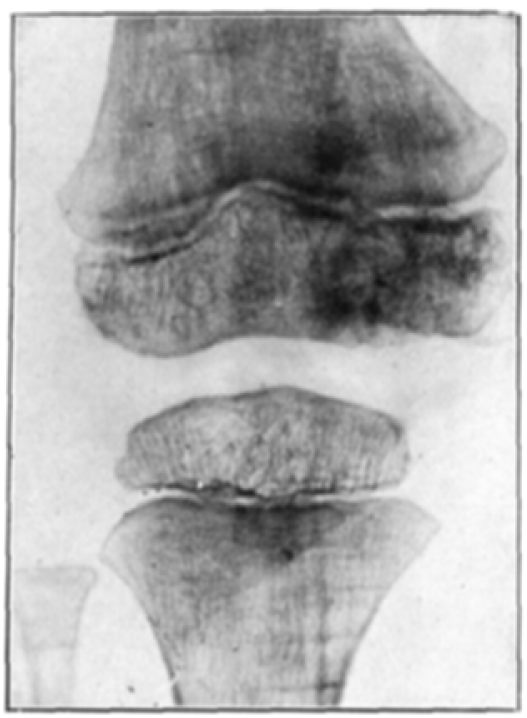

Fig. 4 


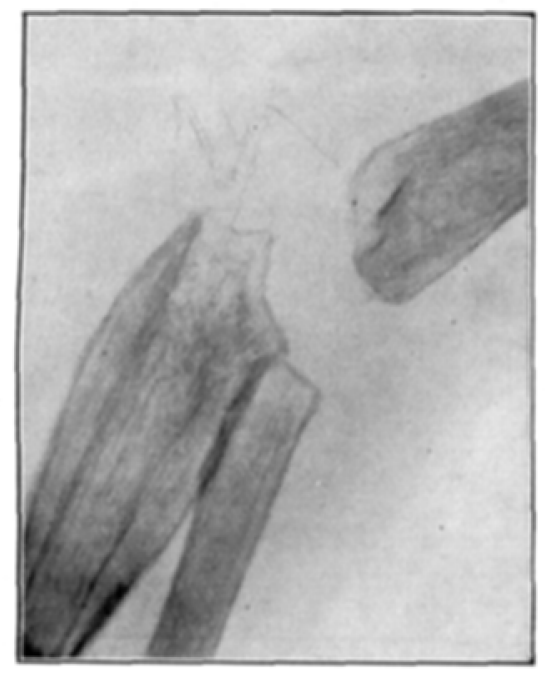

Fig. 5

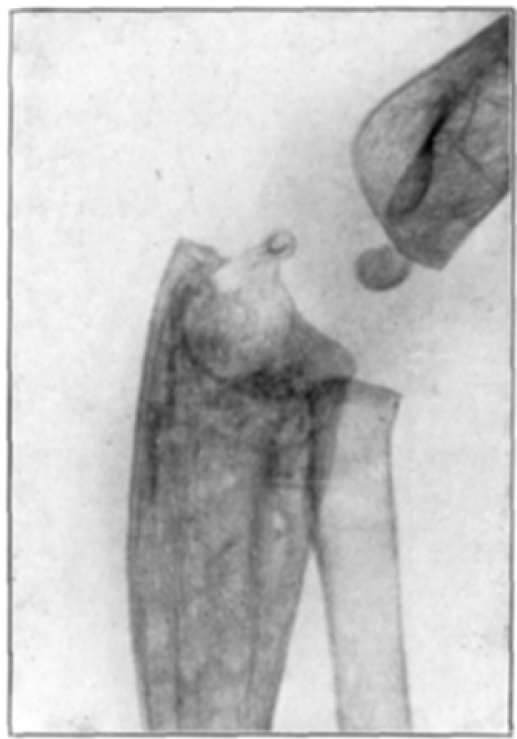

Fig. 6



Fig. 7 


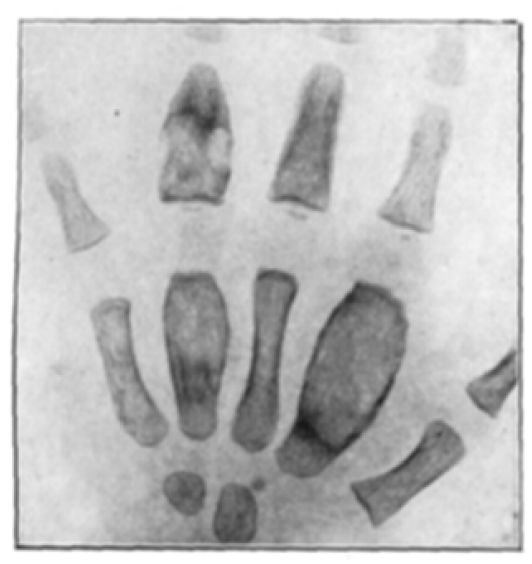

Fig. 8

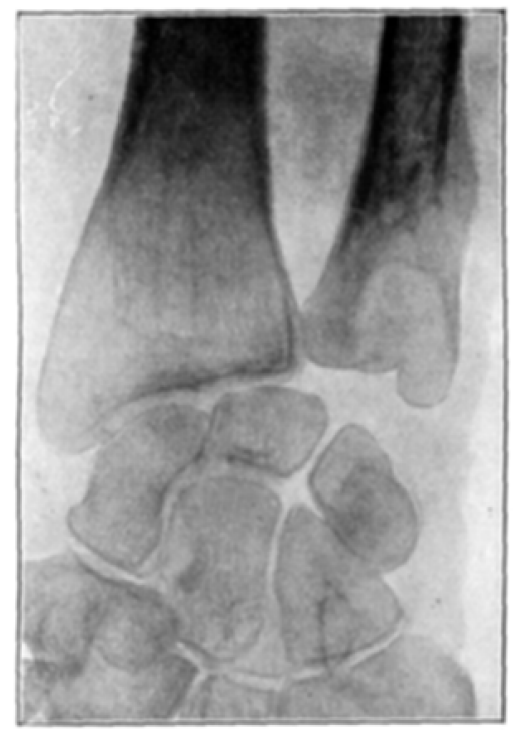

Fig. 10

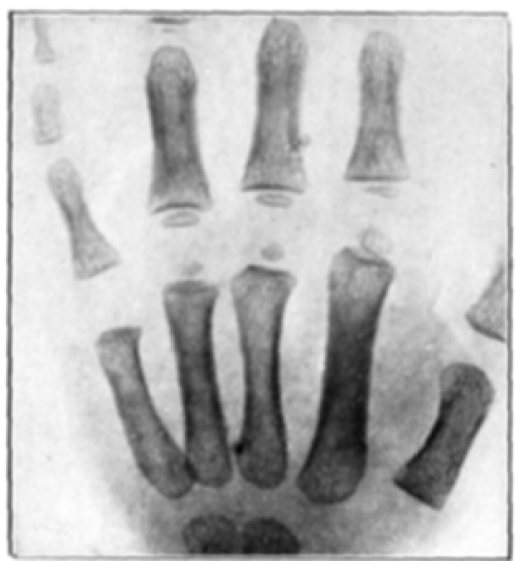

Fig. 9

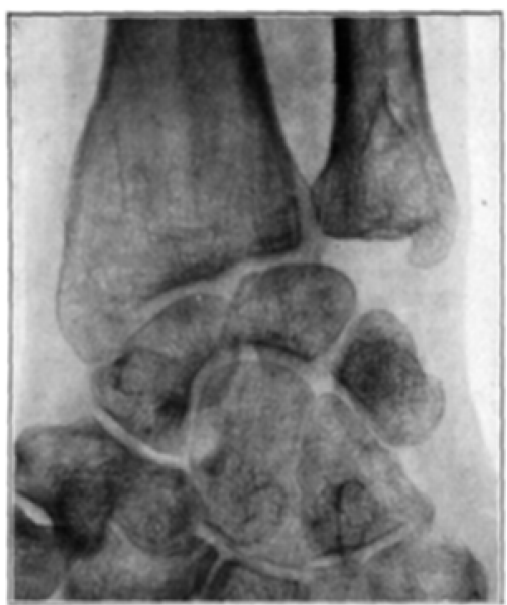

Fig. 11 


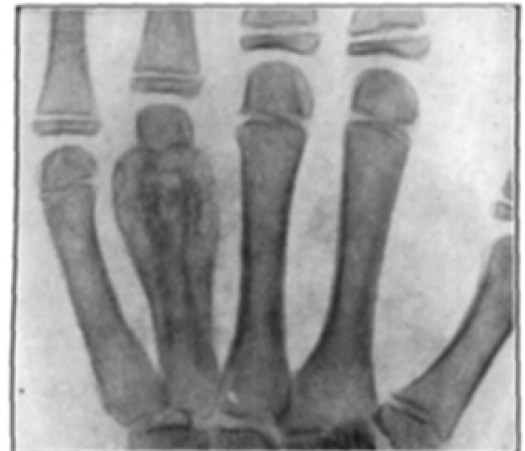

Fig. 12

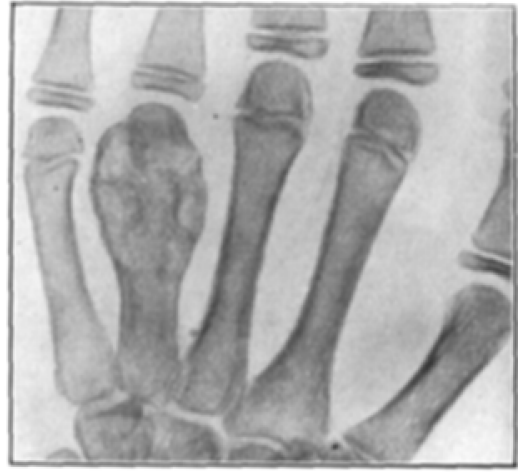

Fig. 13

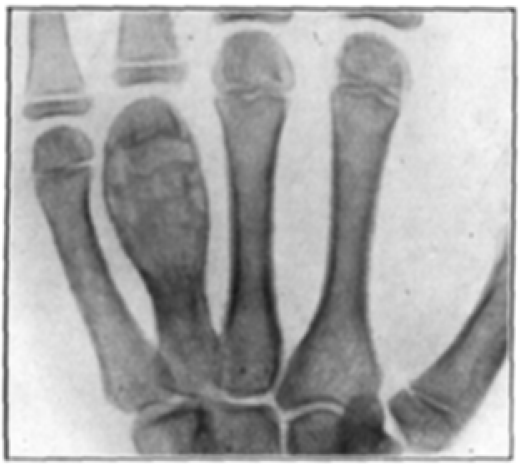

Fig. 14

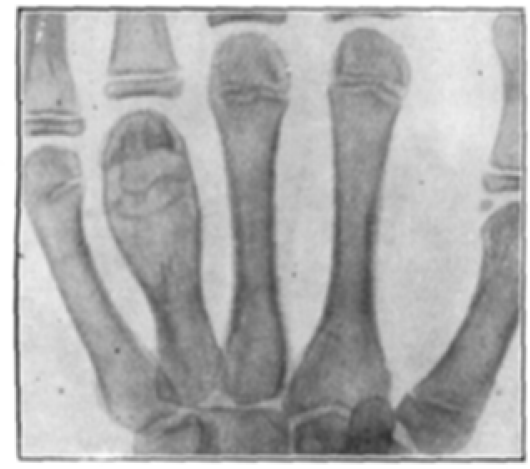

Fig. 15

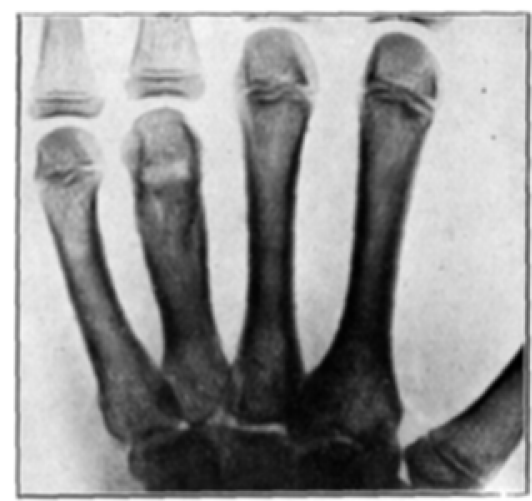

Fig. 16 


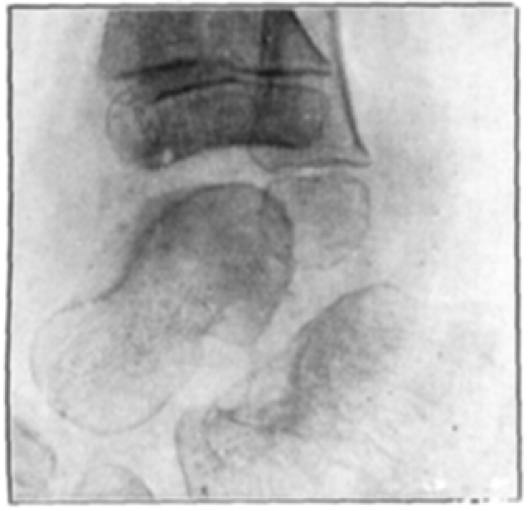

Fig. 17

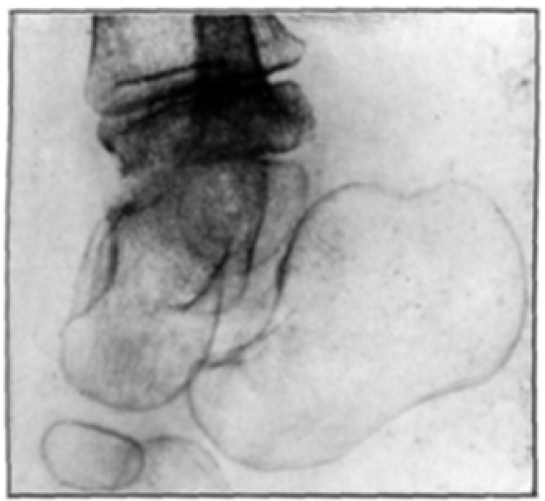

Fig. 19

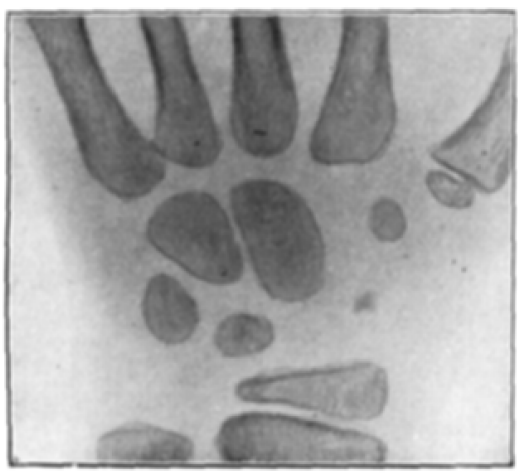

Fig. 21

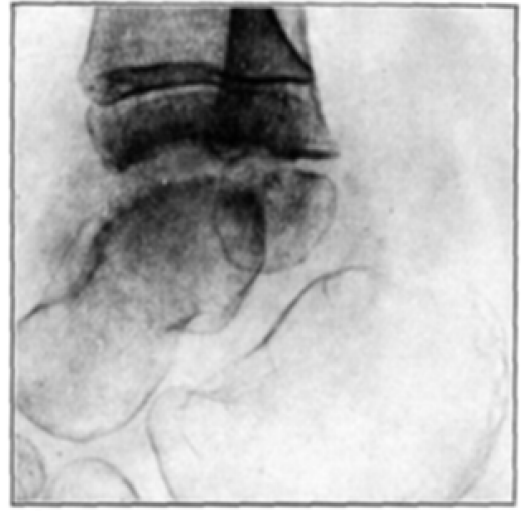

Fig. 18

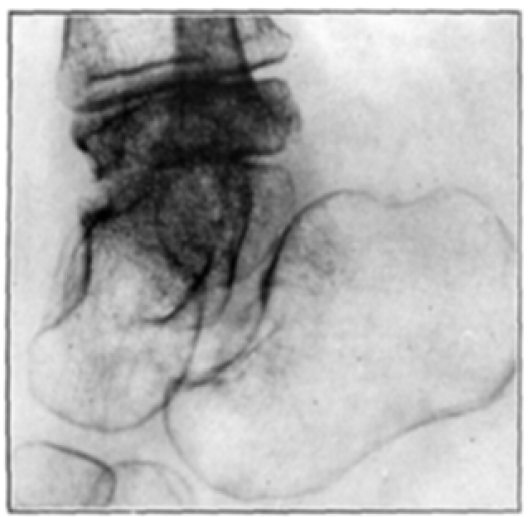

Fig. 20

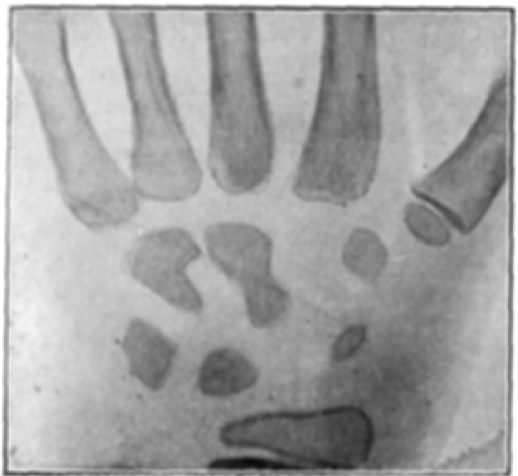

Fig. 22 


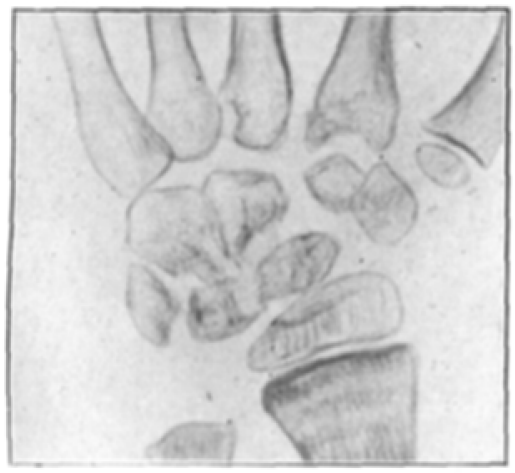

Fig. 23

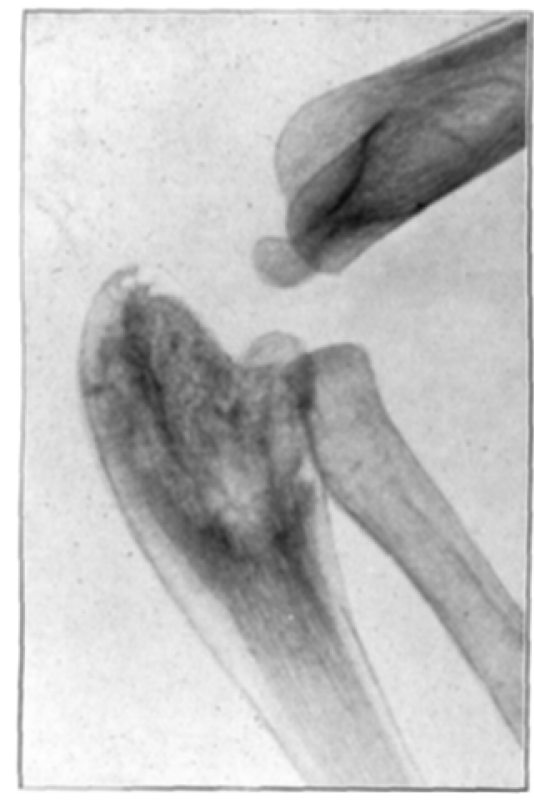

Fig. 25

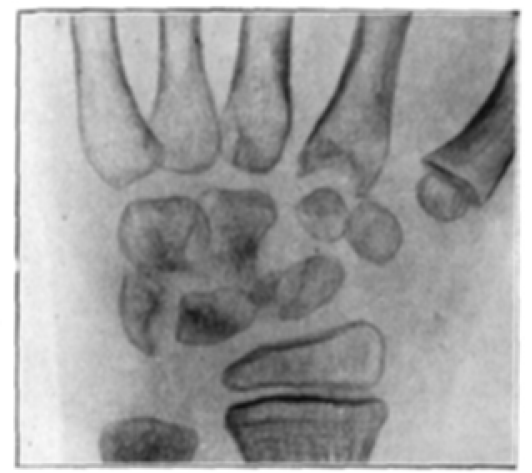

Fig. 24

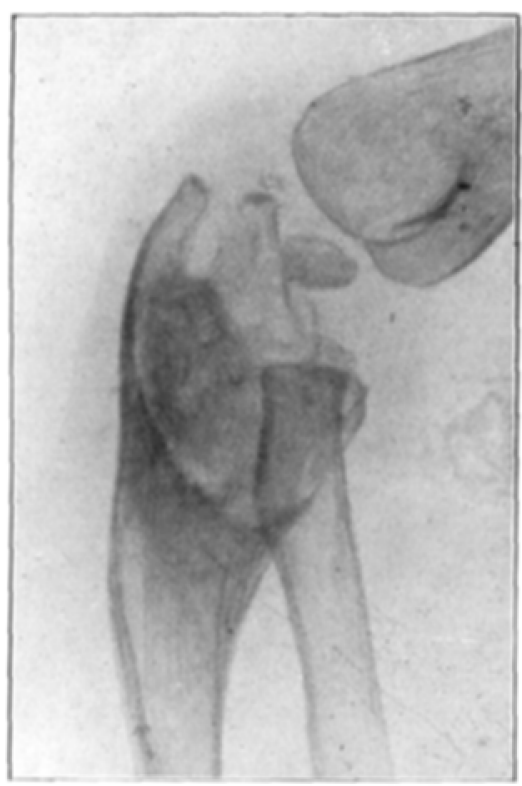

Fig. 26 


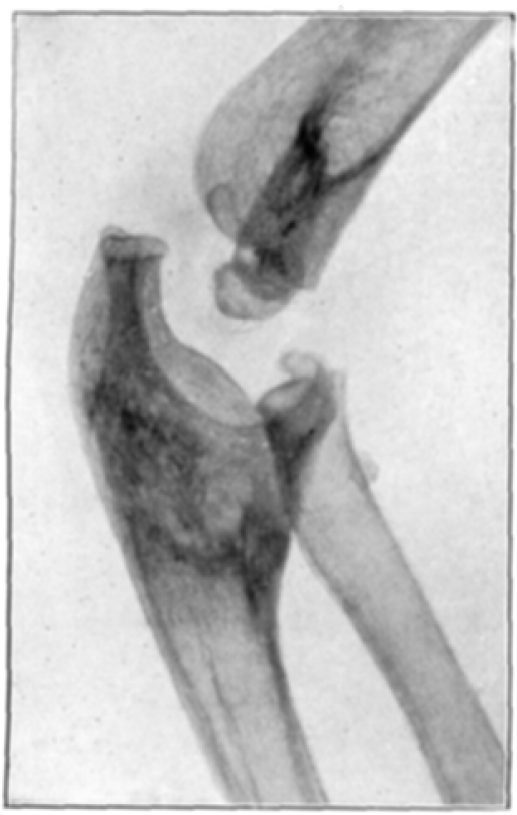

Fig. 27

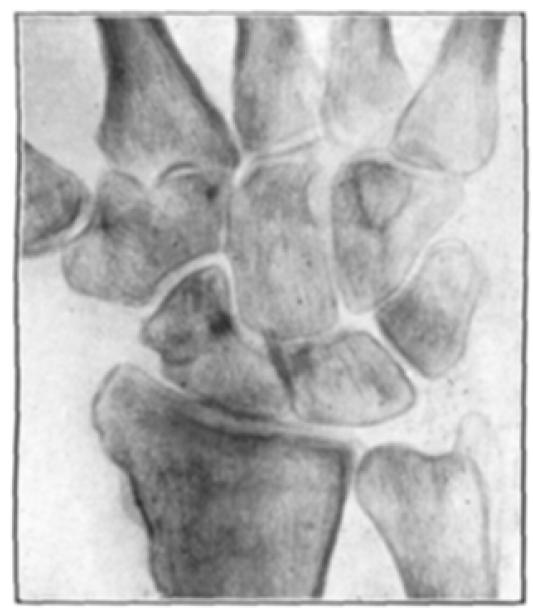

Fig. 29

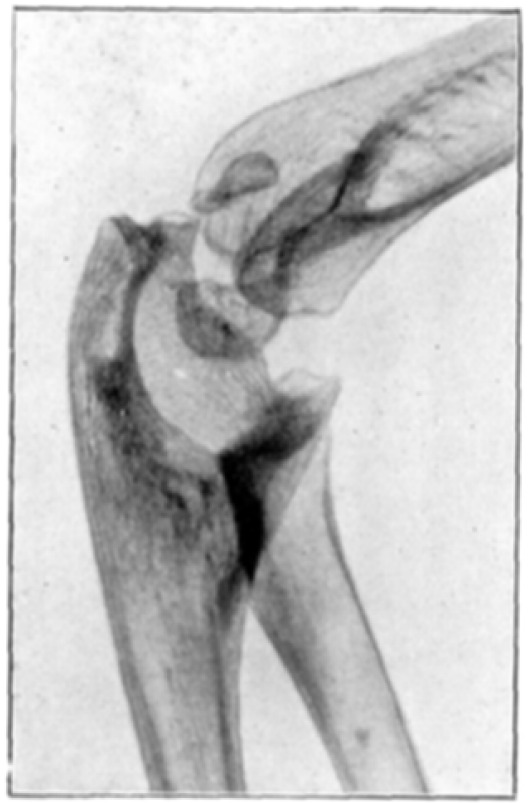

Fig. 28

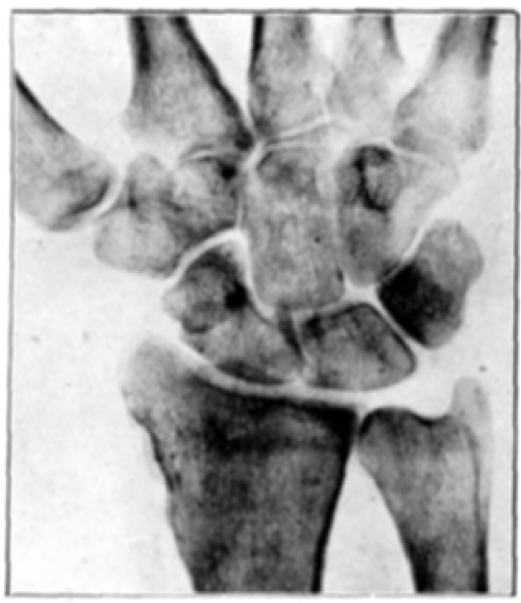

Fig. 30 


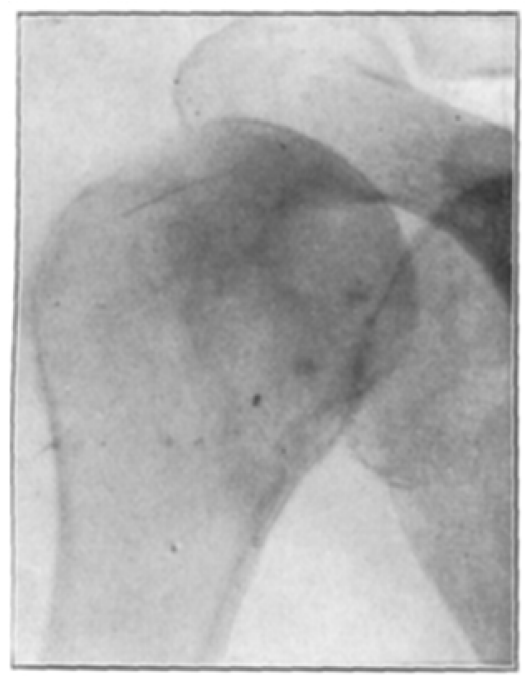

Fig. 31

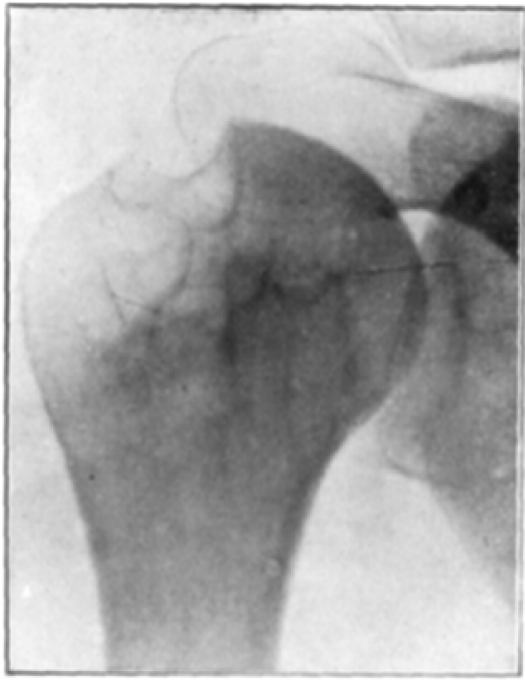

Fig. 32

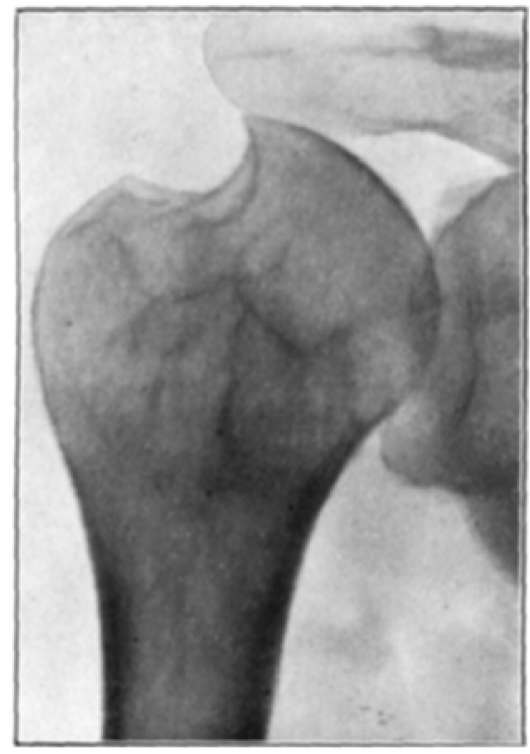

Fig. 33 


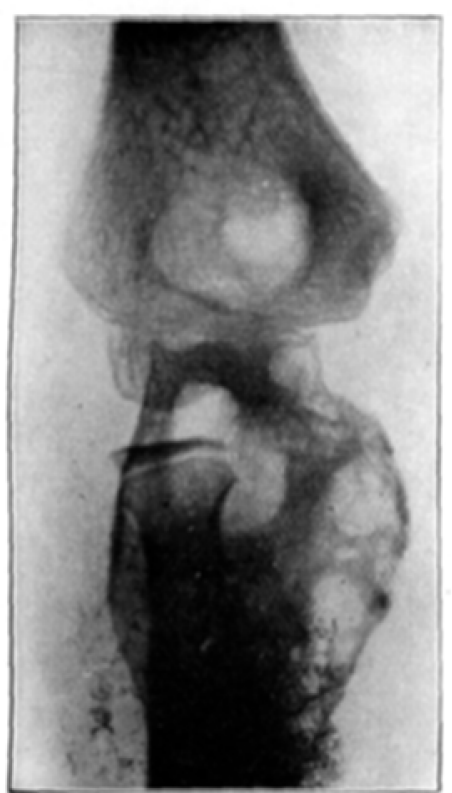

Fig. 34

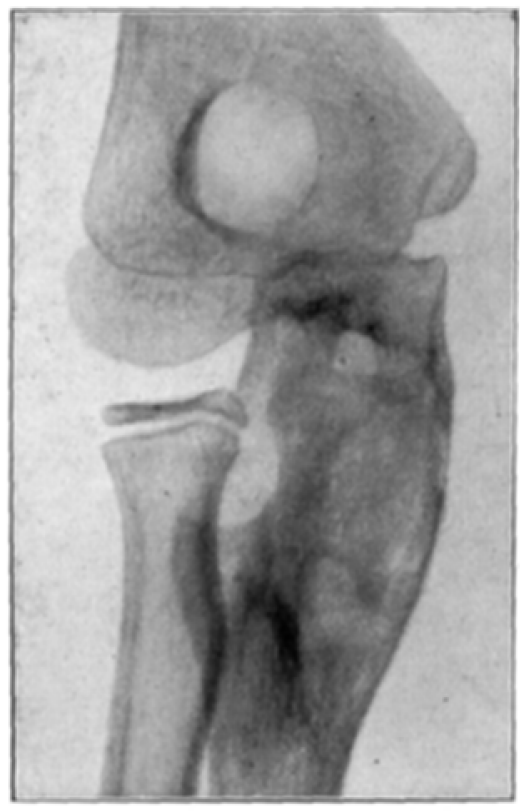

Fig. 35

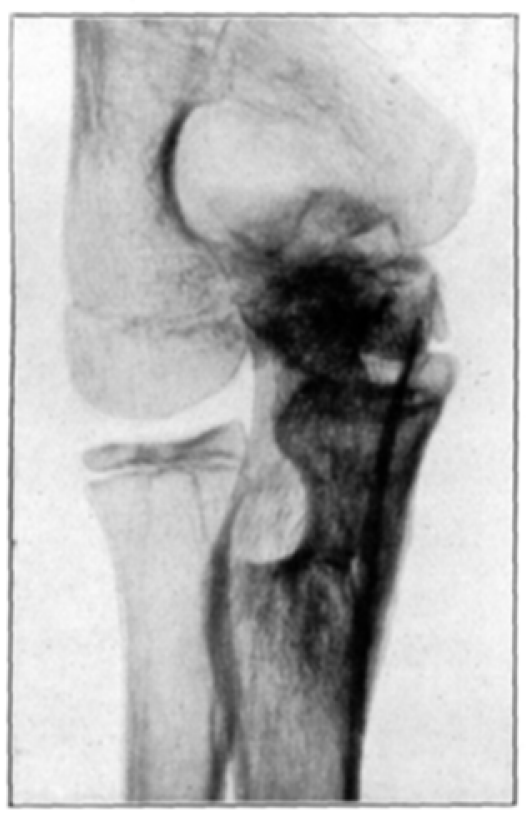

Fig. 36 
nosis; because even very large destructions may be repaired with light treatment (Histories 2, 3, 5, 6, 8, 9, 10, 12).

4) The complete roentgenological healing may occur long after the clinical symptoms have disappeared (History 12).

5) Tuberculous ostitis can heal spontaneously, but under light treatment the result becomes cosmetically and roentgenologically far nicer, and is attained more quickly (Histories 4, 12).

6) Simultaneously with clinical improvement considerable roentgenological deterioration is seen at times. In reality this is merely the sign of the diseased material being resorbed.

7) Extensive arthroitis in hand, ankle, knee, and elbow-joint can heal with new formation of articular cartilage and good function.

8) A joint-end seen deformed roentgenologically can occur simultaneously with a completely free function clinically.

It is with pleasure that in conclusion I ask my chief, Dr Reyn, to accept my best thanks for granting me the use of the material, and for the great interest with which he has followed my work. As mentioned in the introduction, this is only a temporary work, and it is my hope that the steadily increasing material at the Finsen Institute will give me an opportunity of continuing these investigations.

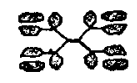

